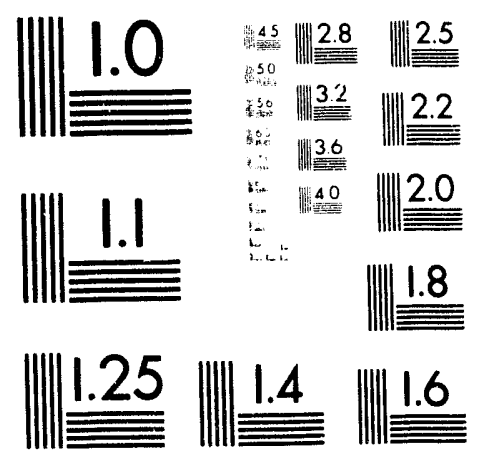



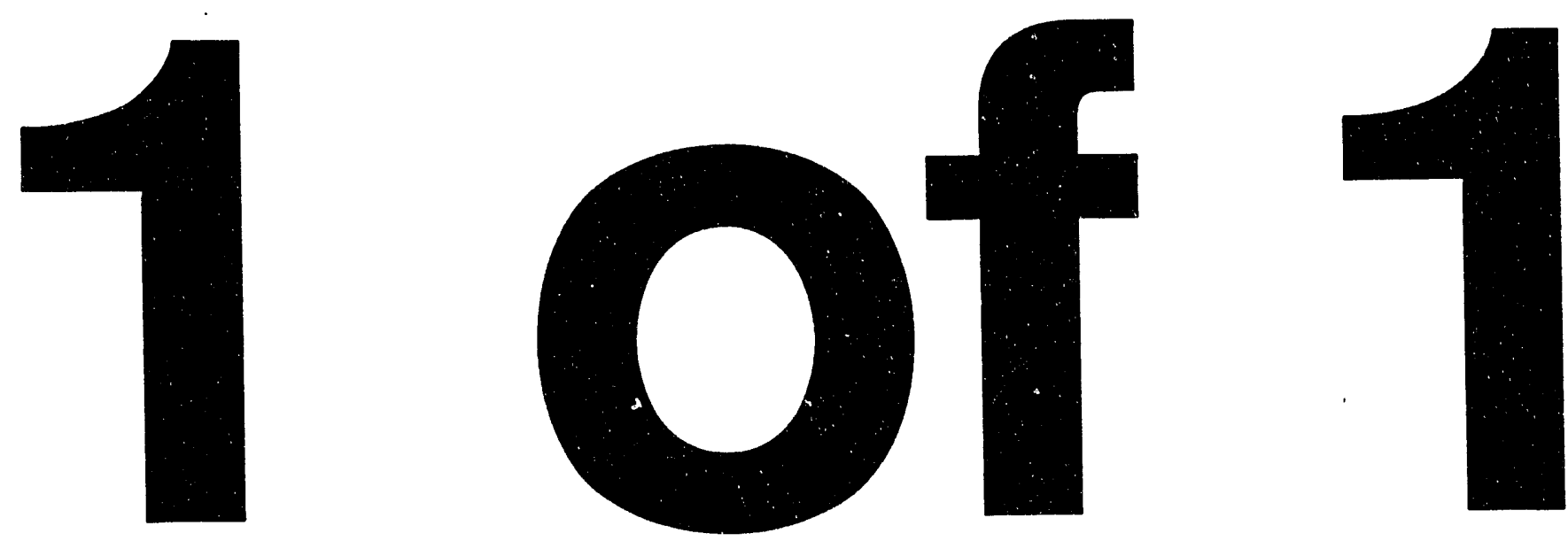


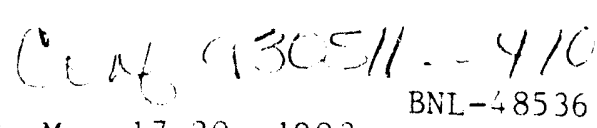

Presented at Particle Accelerator Conference, Washington, DC, May 17-20, 1993

\section{Large Aperture Quadrupoles for RHIC Interaction Regions*}

R. Gupta, M. Anerella, G. Ganetis, M. Garber, A. Ghosh, A. Greene, A. Jain,

S. Kahn, E. Kelly, E. Killian, G. Morgan, A. Morgillo, J. Muratore, A. Prodell, M. Rehak, W. Sampson, R. Shutt, P. Thompson, P. Wanderer, E. Willen

Brookhaven National Laboratory, Upton, NY 11973, USA

\section{Abstract}

The ultimate luminosity performance of the Relativistic Heavy Ion Collider (RHIC) depends on the field quality $i_{i}$ the large aperture $(130 \mathrm{~mm})$ superconducting quadrupoles in the interaction regions ${ }^{1,2}$. In this paper we discuss the design features that are incorporated to obtain a good field quality. Coil midplane gap and pole shims may be adjusted to remove certain field harmonics due to systematic errors in construction. Iron tuning shims will be inserted at eight strategic locations in the assembled magnets to correct the measured values of harmonics in each magnet. The performance of two prototype magnets and upgrades under consideration will be discussed.

\section{INTRODUCTION}

A total of seventy two $130 \mathrm{~mm}$ aperture quadrupoles will be used in 24 focusing triplets in six interaction regions. The parameters of these quadrupoles (Q1, Q2 and $Q 3)$ are shown in table 1 . The beam will be squeezed to the smallest possible size $\left(\beta^{*}=1\right)$ at the crossing point in the two low-beta interaction regions to obtain the highest possible luminosity. An unavoidable consequence of that squeezing is the increase in the beam size in these quadrupoles. Moreover, a rapid variation in the beam size within the focusing triplet limits the effectiveness of the local and lumped global corrector system ${ }^{2}$. Therefore, good field quality large aperture quadrupoles in the interaction regions are crucial to beam life during the high luminosity operation of RHIC. Since the maximum luminosity is desired at the top energy, the field errors will be minimized at the maximum operating gradient.

In quadrupoles, the skew $\left(a_{n}^{\prime}\right)$ and normal $\left(b_{n}^{\prime}\right)$ field harmonics in prime units are defined as follows :

$$
B_{y}+i B_{x}=10^{-4} G \times R \sum_{n=0}^{\infty}\left[b_{n}^{\prime}+i a_{n}^{\prime}\right]\left[\frac{x+i y}{R}\right]^{n}
$$

where $B_{x}$ and $B_{y}$ are the field components at $(x, y), G$ is the gradient at the center of the quadrupole and $R$ is the reference radius, chosen as $40 \mathrm{~mm}$ for these magnets.

\section{BASIC CONSTRUCTION}

In the design of these quadrupoles, the yoke also acts as a collar. A $6.35 \mathrm{~mm}$ thick stainless steel shell is welded after the collaring keys are inserted in the compressed yoke. The space between the coil and yoke is taken by a thin glass filled phenolic spacer. The magnet contains constant perimeter ends in which the turns are uniformly distributed. The two $Q 1$ quadrupoles of the inner and outer rings will share a common cryostat.

*Work supported by U.S. Department of Energy.

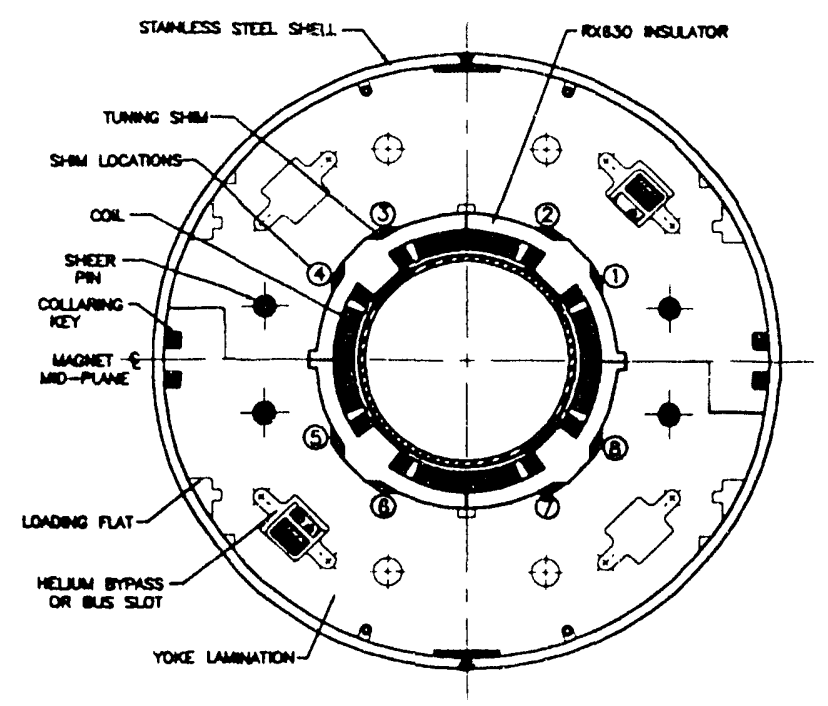

Figure 1: Cross section of the $130 \mathrm{~mm}$ quadrupoles for RHIC interaction region.

Table 1: The basic design parameters of the large aperture quadrupoles for RHIC interaction regions.

\begin{tabular}{|c|c|}
\hline Parameter & Value \\
\hline Superconducting wire diameter & $0.65 \mathrm{~mm}$ \\
\hline Number 'of wires per cable ..... & 36 \\
\hline Copper to superconductor ratio & 1.8 \\
\hline Cable mid-thickness/width .... & $1.16 / 11.7 \mathrm{~mm}$ \\
\hline Cable insulation $\ldots \ldots \ldots \ldots \ldots$ & Kapton $\mathrm{Ci}$ \\
\hline Critical current at $5.6 \mathrm{~T}, 4.2^{\circ} \mathrm{K}$ & $\geq 10100 \mathrm{~A}$ \\
\hline Number of turns per pole ...... & 27 \\
\hline Coil inner diameter $\ldots \ldots \ldots \ldots$ & $130 \mathrm{~mm}$ \\
\hline Coil outer diameter $\ldots \ldots \ldots \ldots$ & $154 \mathrm{~mm}$ \\
\hline Yoke lamination thickness ..... & $6.35 \mathrm{~mm}$ \\
\hline Yoke inner radius at midplane. & $87 \mathrm{~mm}$ \\
\hline Yoke inner radius at pole.... & $92 \mathrm{~mm}$ \\
\hline Yoke outer diameter .......... & $350.5 \mathrm{~mm}$ \\
\hline Magnetic length, Q1, Q2, Q3 .. & $1.44,3.4,2.1 \mathrm{~m}$ \\
\hline Min. beam spacing in triplet .. & $424 \mathrm{~mm}$ \\
\hline Design current $\ldots \ldots \ldots \ldots \ldots$ & $5.0 \mathrm{kA}$ \\
\hline Design gradient $\ldots \ldots \ldots \ldots \ldots$ & $48.1 \mathrm{~T} / \mathrm{m}$ \\
\hline Operating temperature $\ldots \ldots \ldots$ & $4.6^{\circ} \mathrm{K}$ \\
\hline Computed quench gradient .... & $75.3 \mathrm{~T} / \mathrm{m}$ \\
\hline Field margin $\ldots \ldots \ldots \ldots \ldots$ & $57 \%$ \\
\hline
\end{tabular}

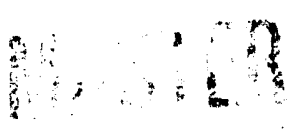

DISTRIBUTION OF THIS DOCUMETT iS UNVLINATIED 


\section{CROSS SECTION}

The quadrupole cross section is shown in Fig 1 . The coil has a total of 27 turns per octant in three blocks. The coil midplane gap has been increased from a minimum 0.1 $\mathrm{mm}$ to $0.2 \mathrm{~mm}$ in the iterated cross section. Any change in coil size in production magnets will be accommodated by changing the midplane gap by about $40 \%$ of that amount and the pole shim by about $60 \%$. This would result in the same pre-compression and the same $b_{5}^{\prime}$. In addition, a variation in midplane gap and a variation in pole shim size provides a simple but powerful tool for tuning the field harmonics ir. production magnets without changing the basic coil cross section.

In cosine $\theta$ magnets, the iron aperture is circular. However, in o:der to reduce $b_{5}^{\prime}$ saturation we have designed a yoke where the aperture is defined by two radii $-87 \mathrm{~mm}$ at the midplane and $92 \mathrm{~mm}$ at the pole. This has been very effective in reducing the $b_{5}^{\prime}$ saturation from 15 to 1 unit. It forces an early saturation at the yoke midplane and delays/reduces at the pole.

There is a phenolic spacer between the coil outer diameter and yoke inner diameter having a width of 10 $\mathrm{mm}$ at the midplane and $15 \mathrm{~mm}$ at the pole. However, there are eight places where there is a $\sim 7 \mathrm{~mm}$ wide space between the spacer and the yoke. These spaces will be used for accommodating the magnetic tuning shims, as shown in Fig. 1. The other holes and cutouts in the yoke have been placed such that the symmetry breaking harmonics are less than 0.1 unit in the design range of operation. The cross talk induced harmonics (by the quadrupole in the other ring) are also less than 0.1 unit.

\section{SHIMMING}

The random errors in harmonics are primarily determined by the limits in the accuracy of the parts and the process used in manufacturing the superconducting magnets. To overcome these limitations, we have developed a method of shimming. The basic principle of this is to insert the iron shims in the eight suitable locations between the phenolic spacer outer radius and the yoke inner radius to reduce the measured harmonics. The approximate angular location of shim No. 1 is $30^{\circ}$, No. 2 is $60^{\circ}$, No. 3 is $120^{\circ}$, etc., as shown in Fig. 1. Since the harmonics will be corrected magnet by magnet, the method will also reduce any systematic value, if present.

Methods based on the same general principle have been used before in conventional magnets. It is more complicated in superconducting magnets because (a) there is usually no access to the iron aperture and (b) when the magnet is opened and assembled again the harmonics are not reproduced at the desired level. However, the design of the RHIC large aperture quadrupoles is such that the eight iron shims can be inserted easily without opening the magnet after the magnetic measurements are performed. The actual shim package will always be molded to the same thickness but a part of it will be made of magnetic steel (laminated and insulated) and the rest will be made of the non-magnetic material brass.
The maximum space available for the magnetic tuning shim is $\sim 6.6 \mathrm{~mm}$. The nominal design has $3.3 \mathrm{~mm}$ of magnetic and $3.3 \mathrm{~mm}$ of non-magnetic material. All changes in shim size will be made relative to the nominal $3.3 \mathrm{~mm}$ of magnetic material. In table 2, we have listed the maximum amount of correction possible in each harmonic with $+1 \mathrm{~mm}$ and/ur $-1 \mathrm{~mm}$ relative change in shim. The locations which produce a maximum positive value for each harmonic for this relative change is also shown. Some of the harmonics listed in table 2 are coupled to each other, e.g. $b_{3}^{\prime}$ and $b_{7}^{\prime}$ (in general, harmonics $2 n+1$ and $2 n+5$ with $n=0,1,2, \ldots)$. This means that if $b_{3}^{\prime}$ is changed, $b_{7}^{\prime}$ will also change according to the $b_{3}^{\prime} / b_{7}^{\prime}$ ratio given in table 2. Therefore, the eight shims can not be used to make any arbitrary eight harmonics zero. But the correction in the "skew and normal" harmonics and in the "odd and even" harmonics are orthogonal to each other. Therefore, one can still make the desired eight harmonics $\left(a_{2}^{\prime}, a_{3}^{\prime}, a_{4}^{\prime}, a_{5}^{\prime}\right.$ and $\left.b_{2}^{\prime}, b_{3}^{\prime}, b_{4}^{\prime}, b_{5}^{\prime}\right)$ independently zero. Since adequate space for shimming is available, the correction will only be limited by the acceptance in the higher order harmonics generated in the process.

A computer program $S H I M C A L$ has been written to compute the values of eight shims to minimize an error function consisting of measured and desired values of field harmonics. The harmonics will be corrected for the top energy operation; at injection there will be about $10 \%$ over-correction to account for the loss due to iron saturation. In mass production, the correction will be based on warm measurements. However, a warm to cold ( $5 \mathrm{kA}$ ) correlation will be developed in the beginning.

Table 2: Maximum change possible by $+1 \mathrm{~mm}$ and/or $-1 \mathrm{~mm}$ relative change in shim size at the given locations at $5.0 \mathrm{kA}$. Shim locations 1,2 , etc. are shown in Fig 1.

\begin{tabular}{|c|c|c|c|c|c|}
\hline & $\begin{array}{c}+1 /-1 \mathrm{~mm} \\
\text { locations }\end{array}$ & $\begin{array}{c}\text { Change } \\
\text { (Units) }\end{array}$ & $\begin{array}{c}+1 /-1 \mathrm{~mm} \\
\text { locations }\end{array}$ & $\begin{array}{c}\text { Change } \\
\text { (Units) }\end{array}$ \\
\hline$a_{0}^{\prime}$ & $1234 / 5678$ & 18.64 & $b_{0}^{\prime}$ & $1278 / 3456$ & 18.64 \\
\hline$a_{1}^{\prime}$ & $1357 / 2468$ & 8.37 & $b_{1}^{\prime}$ & All/None & 22.50 \\
\hline$a_{2}^{\prime}$ & $5678 / 1234$ & 9.85 & $b_{2}^{\prime}$ & $1278 / 3456$ & 9.85 \\
\hline$a_{3}^{\prime}$ & $3478 / 1256$ & 7.37 & $b_{3}^{\prime}$ & $1458 / 2367$ & 6.36 \\
\hline$a_{4}^{\prime}$ & $2358 / 1467$ & 2.99 & $b_{4}^{\prime}$ & $1368 / 2457$ & 2.99 \\
\hline$a_{5}^{\prime}$ & $2468 / 1357$ & 2.52 & $b_{5}^{\prime}$ & None/All & 1.22 \\
\hline$a_{6}$ & $2358 / 1467$ & 1.0 & $b_{6}^{\prime}$ & $2457 / 1368$ & 1.0 \\
\hline$a_{7}^{\prime}$ & $1256 / 3478$ & 0.04 & $b_{7}^{\prime}$ & $2367 / 1458$ & 0.72 \\
\hline$a_{8}^{\prime}$ & $1467 / 2358$ & 0.25 & $b_{8}^{\prime}$ & $2457 / 1368$ & 0.25 \\
\hline$a_{9}^{\prime}$ & $1357 / 2468$ & 0.16 & $b_{9}^{\prime}$ & None/All & 0.08 \\
\hline
\end{tabular}

\section{MEASUREMENTS, ANALYSIS AND UPGRADES}

The quench performance of the two pre-production quadrupoles QRI001 and QRI002 is shown in Fig 2. The first quench occurs at $28 \%$ above the maximum operating current. Though not critical to the machine operation, the quench performance is expected to improve significantly 


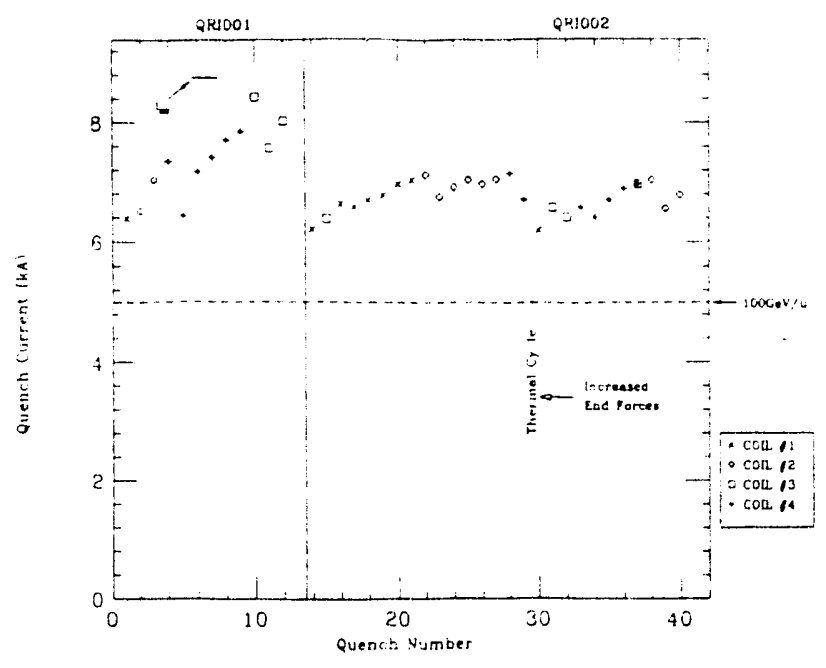

Figure 2: Quench performance of the pre-production quadrupoles QRI001 and QRI002.

in QRI002 rebuild and in production magnets when the pole lead, just coming out of the straight section, is solder filled and thus better supported.

The azimuthal stress on the coil has been measured at all eight pole locations. The average stress was 10.5 kpsi $(72.3 \mathrm{MPa})$ at room temperature. A significantly higher ( $3 \mathrm{kpsi}$ ) stress has been observed in the four strain gauges located nearest to the horizontal plane. After the cool down the average stress was $3.3,2.1$ and $1.5 \mathrm{kpsi}$ at a current of 0,5 and $6.6 \mathrm{kA}$; the asymmetry in stress data persisted. The ends were pre-loaded by a varying amount in two magnets and in a rebuild of QRI002; no unusual behavior was noted.

In table 3 , we have given the average values of measured harmonics in QRI001 and QRI002. The harmonics in the two magnets were quite close to each other. The body (straight section), lead end and return end harmonics are derived from the measurements at several locations with a 0.229 meter long measuring coil. For computing integral harmonics (in units), the end harmonics must be divided by the magnetic length of Q1, Q2 and Q3 before ad. "ag to the body harmonics in table 3 . The presence of a large $b_{3}^{\prime}$ in the body will be discussed later. The non-zero $b_{5}^{\prime}$ and $b_{9}^{\prime}$ in the body are due to a change in the insulated cable thickness after the design. The cross section has been iterated to reduce these harmonics for the production magnets. The large $a_{5}^{\prime}$ and $b_{5}^{\prime}$ in the lead end are caused by eight $\sim 0.2$ meter long leads connecting the four coils. A new lead design is expected to reduce most of these harmonics by a factor of three. A current dependence due to iron saturation has been observed in the allowed quadrupole harmonics. The difference between 2 $\mathrm{kA}$ and $5 \mathrm{kA}$ is $-0.47 \%$ in transfer function $(G / I), 0.3$ unit in $b_{5}^{\prime}$ and 0.2 unit in $b_{9}^{\prime}$. A small value in $b_{5}^{\prime}$ saturation means that the two radii method for reducing iron saturation in quadrupoles has worked well.
Table 3: Average values of the measured field harmonics in the two pre-production magnets QRI001 and QRI002 in the body (see text), lead end and return end.

\begin{tabular}{|c|c|c|c|c|c|c|c|}
\hline & Body & $\begin{array}{c}\text { Lead } \\
\text { end }\end{array}$ & $\begin{array}{c}\text { Return } \\
\text { end }\end{array}$ & & Body & $\begin{array}{c}\text { Lead } \\
\text { end }\end{array}$ & $\begin{array}{c}\text { Return } \\
\text { end }\end{array}$ \\
\hline & units & $\begin{array}{c}\text { units } \\
\times \mathrm{m}\end{array}$ & $\begin{array}{c}\text { units } \\
\times \mathrm{m}\end{array}$ & & units & $\begin{array}{c}\text { units } \\
\times \mathrm{m}\end{array}$ & $\begin{array}{c}\text { units } \\
\times \mathrm{m}\end{array}$ \\
\hline$a_{2}^{\prime}$ & 0.09 & -2.51 & 1.44 & $b_{2}^{\prime}$ & 0.51 & -0.10 & 0.33 \\
\hline$a_{3}^{\prime}$ & 0.28 & 0.36 & 0.08 & $b_{3}^{\prime}$ & 6.89 & -0.29 & -0.10 \\
\hline$a_{4}^{\prime}$ & 0.03 & 0.13 & 0.23 & $b_{4}^{\prime}$ & 0.30 & 0.13 & 0.04 \\
\hline$a_{5}^{\prime}$ & 0.39 & -4.92 & -0.08 & $b_{5}^{\prime}$ & 7.02 & 8.44 & 1.45 \\
\hline$a_{6}^{\prime}$ & -0.08 & -0.06 & 0.05 & $b_{6}^{\prime}$ & 0.04 & 0.01 & 0.05 \\
\hline$a_{7}^{\prime}$ & -0.02 & -0.02 & -0.01 & $b_{7}^{\prime}$ & 0.03 & 0.04 & 0.01 \\
\hline$a_{8}^{\prime}$ & 0.05 & -0.01 & -0.01 & $b_{8}^{\prime}$ & -0.03 & 0.04 & 0.02 \\
\hline$a_{9}^{\prime}$ & 0.02 & 0.15 & 0.03 & $b_{9}^{\prime}$ & -1.22 & 0.26 & 0.02 \\
\hline
\end{tabular}

The actual position of the wires in the assembled magnet was measured by a coordinate measuring machine from a cross sectional slice cut from the magnet QRI001. The analysis shows that the centers of the upper and lower coil halves were away from the horizontal axis by $\sim 0.25 \mathrm{~mm}$. The coils were bent inward by about the same amount in the horizontal plane. Analysis of the yoke inner surface shows a similar behavior. The bending is thought to be the result of applying compression on the coils through the yoke loading flat. The quadrupole symmetry is broken by this deformation, and a positive $b_{3}^{\prime}$ is created. A similar $b_{3}^{\prime}$ has been observed in the 80 mm aperture RHIC arc quadrupoles based on a similar design. This $b_{3}^{\prime}$ was successfully reduced to a small value in those quadrupoles by using an asymmetric midplane gap between the horizontal and vertical plane. However, in these quadrupoles, we can also use the magnetic tuning shims. A final choice, or a combination of the two, would depend on which scheme produces a smaller $b_{7}^{\prime}$.

\section{CONCLUSICNS}

The field quality in superconducting magnets can be significantly improved by using the techniques described in this paper. The magnetic tuning shims can be used to correct a number of harmonics after the field measurements without opening the magnet. The midplane gap and pole shims can be used to control the field harmonics in addition to accommodating the variations in coil sizes. These techniques are specially suited for the interaction region quadrupoles where a few magnets basically determine the ultimate luminosity performance of the machine.

\section{REFERENCES}

1. R.C. Gupta, et. al., "RFIC Insertion Magnets", Proceedings of the IEEE 1991 Particle Accelerator Conference, San Francisco, May 6-9, 1991 (Page 2239-2241). 2. J. Wei, R. Gupta, S. Peggs, "Magnetic Multipole Compensation for the RHIC Triplets", Paper Ga86, this conference (PAC 1993). 


\section{DISCLAIMER}

This report was prepared as an account of work sponsored by an agency of the United States Government. Neither the United States Gnvernment nor any agency thereof, nor any of their employees, makes any warranty, express or implied, or assumes any legal liability or responsibility for the accuracy, completeness, or usefulness of any information, apparatus, product, or process disclosed, or represents that its use would not infringe privately owned rights. Reference herein to any specific commercial product, process, or service by trade name, trademark, manufacturer, or otherwise does not necessarily constitute or imply its endorsement, recommendation, or favoring by the United States Government or any agency thereof. The views and opinions of authors expressed herein do not necessarily state or reflect those of the United States Government or any agency thereof. 

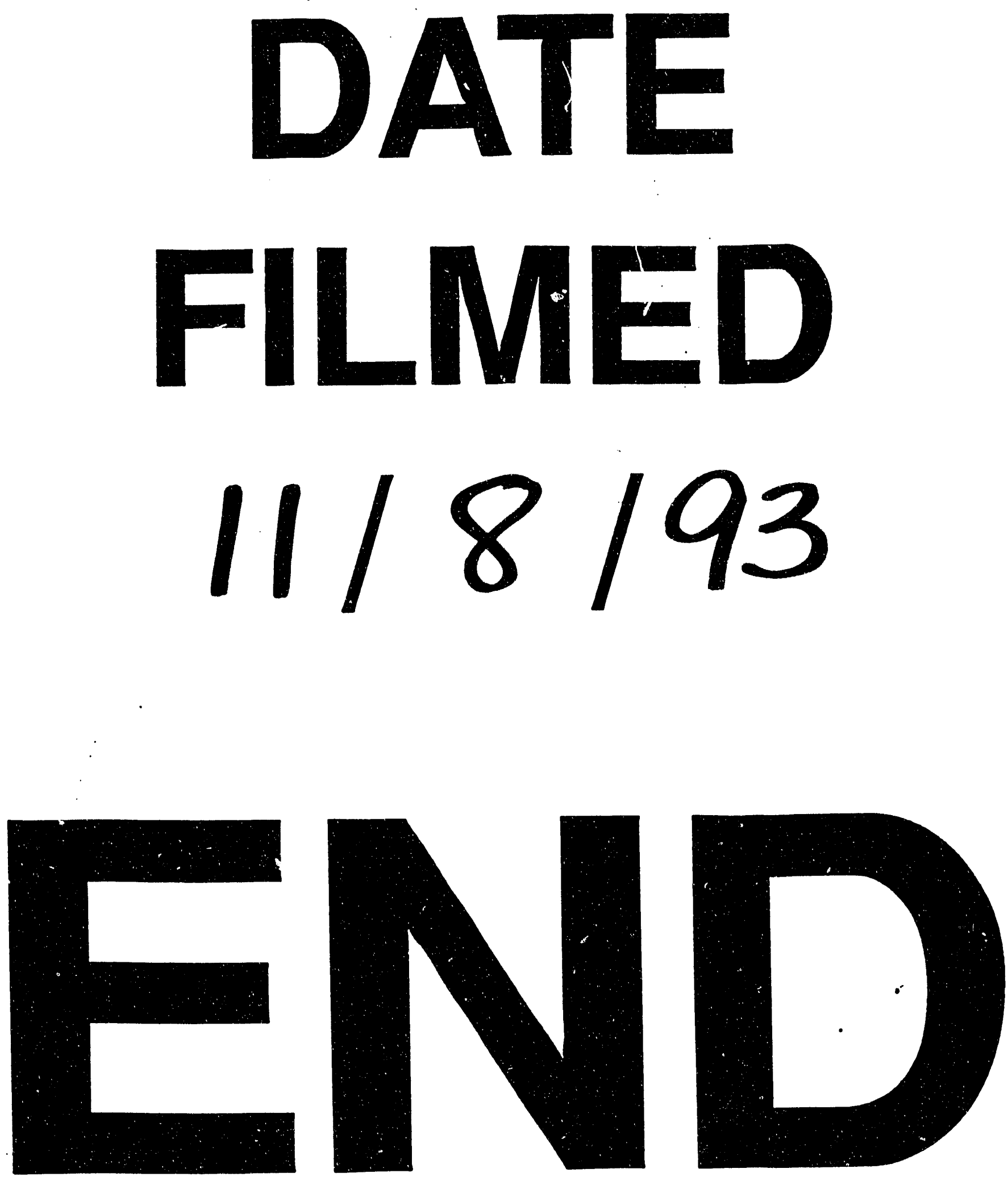
